\title{
Avian Viral Pathogens in Swallows, Zimbabwe
}

\section{Infectious Diseases in Hirundinidae: A Risk to Swallow?}

\author{
A. Caron,${ }^{1,2}$ N. Chiweshe, ${ }^{3}$ J. Mundava, ${ }^{4}$ C. Abolnik, ${ }^{5}$ A. Capobianco-Dondona, ${ }^{6}$ M. Scacchia,${ }^{6}$ and N. Gaidet ${ }^{1}$ \\ ${ }^{1}$ UMR117, Département Environnements et Sociétés, Cirad, TA 30/E Campus International de Baillarguet, 34398 Montpellier, France \\ ${ }^{2}$ Research Platform Production and Conservation in Partnership, Faculdade de Veterinaria, Universidade Eduardo Mondlane, Av. de Moçambique Km. \\ 1,5, Caixa Postal 257, 01009 Maputo, Mozambique \\ ${ }^{3}$ Research Platform Production and Conservation in Partnership, Cirad, University of Zimbabwe, Harare, Zimbabwe \\ ${ }^{4}$ National University of Science and Technology, PO Box AC 939, Ascot, Bulawayo, Zimbabwe \\ ${ }^{5}$ Poultry Section, Department of Production Animal Studies, Faculty of Veterinary Science, University of Pretoria, Onderstepoort 0110, South Africa \\ ${ }^{6}$ Istituto Zooprofilattico Sperimentale dell'Abruzzo e del Molise "G. Caporale", Campo Boario, 64100 Teramo, Italy
}

\begin{abstract}
We sampled 417 swallows in a wetland ecosystem of Zimbabwe in February 2010 and October 2011. RT-PCR tests revealed circulation of avian paramyxovirus type I, avian influenza and West Nile disease viruses in these populations. We discuss the relevance of these findings in relation to what is known on the epidemiology of these viruses in these hosts and in relation to the host ecology. We conclude with recommendations to focus more research on Passeriformes in disease ecology and in particular on the hirundinidae family.
\end{abstract}

Keywords: Hirundinidae, Avian influenza, Newcastle disease virus, West Nile virus, Wild birds

The contribution of wild bird species to the transmission and maintenance of multi-host pathogens, including avian paramyxovirus type I (causing Newcastle disease- $\mathrm{NCD}$ ), avian influenza (AIV) and West Nile disease (WNV) viruses, remains poorly known. There are more than 10,000 wild bird species worldwide (Boyd 2015) with highly diverse life-history traits and ecology (i.e. social, foraging or movement behaviour), resulting in heterogeneous competence among species for pathogen transmission. Poor understanding of the relative role of wild birds in multiple

Correspondence to: A. Caron, e-mail: alexandre.caron@cirad.fr disease ecology can therefore compromise surveillance and control efforts.

The family hirundinidae is composed of 83 swallow and martin species with several ecological traits that could promote pathogen transmission and spread over large geographic regions (Viana et al. 2016). They are cosmopolitan, breeding on all continents except Antarctica and on many islands. Many species are long-distance migrants that connect the Northern and Southern hemispheres. For example, some barn swallow (Hirundo rustica) populations breed in temperate regions of northern Europe and overwinter in Africa, after a migration approaching $10,000 \mathrm{kms}$. They are usually highly gregarious and at some sites congregate in mono- or multi-species roosts of mil- 


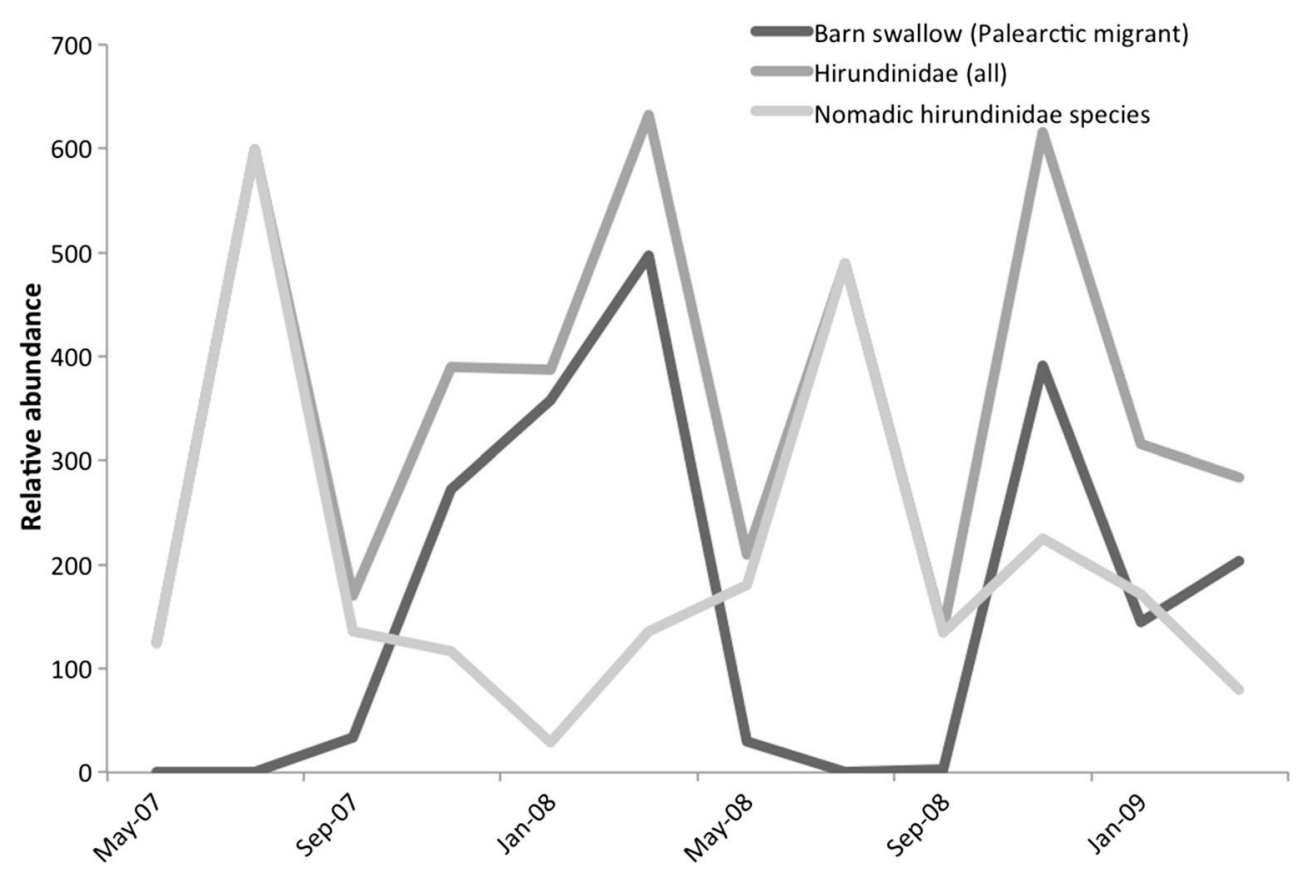

Figure 1. Population dynamics of hirundinidae in the Lake Manyame and Chivero, Zimbabwe (the study site), during 2 years preceding the epidemiological study. Based on focal count of $30 \mathrm{~min}$, four times per counting week per site ( $n=14$ sites), a week every 2 months during 2 years (for more details see Caron et al. 2010). Dark grey: barn swallow (Palearctic migrant); grey: all hirundinidae species counted on sites $(n=6)$; light grey: nomadic and resident hirundinidae species $(n=5)$. The vertical axis is a proxy of relative abundance across the sites.

Table 1. RT-PCR Results of 417 Hirundinidae Cloacal Samples for Avian Influenza Viruses (AIV), Avian Paramyxovirus Type 1 (APMV-1) and West Nile Viruses, (WNV) Captured and Sampled During Two Sampling Sessions in a Roosting Site (S17 ${ }^{\circ} 49,917$; $\left.\mathrm{E} 030^{\circ} 40,242\right)$.

\begin{tabular}{|c|c|c|c|c|c|c|c|c|c|c|c|c|c|c|}
\hline \multirow[t]{3}{*}{$\begin{array}{l}\text { Common name } \\
\text { Latin name }\end{array}$} & \multicolumn{7}{|c|}{$\begin{array}{l}\text { February } 2010 \text { (Before migration to Northern } \\
\text { hemisphere) }\end{array}$} & \multicolumn{7}{|c|}{ October 2011 (After arrival from Northern hemisphere) } \\
\hline & \multirow[t]{2}{*}{$n$} & \multicolumn{2}{|l|}{ AIV } & \multicolumn{2}{|c|}{ APMV-1 } & \multicolumn{2}{|c|}{ WNV } & \multirow[t]{2}{*}{$n$} & \multicolumn{2}{|l|}{ AIV } & \multicolumn{2}{|c|}{ APMV-1 } & \multicolumn{2}{|c|}{ WNV } \\
\hline & & Pos. & Inf. ratio & Pos. & Inf. ratio & Pos. & Inf. ratio & & Pos. & Inf. ratio $(\%)$ & Pos. & Inf. ratio & Pos. & Inf. ratio $(\%)$ \\
\hline $\begin{array}{l}\text { Barn swallow } \\
\text { Hirundo rustica }\end{array}$ & 133 & 4 & $\begin{array}{l}3.0 \% \\
{[0.1-5.9]}\end{array}$ & 2 & $\begin{array}{l}1.5 \% \\
{[0.0-3.6]}\end{array}$ & 8 & $\begin{array}{l}6.0 \% \\
{[2.0-10.1]}\end{array}$ & 17 & 0 & 0.0 & 1 & $\begin{array}{l}5.9 \% \\
{[0.0-17.4]}\end{array}$ & 0 & 0.0 \\
\hline $\begin{array}{l}\text { Brown-throated martin } \\
\text { Riparia paludicola }\end{array}$ & 74 & 1 & $\begin{array}{l}1.4 \% \\
{[0.0-4.0]}\end{array}$ & 0 & $0.0 \%$ & 3 & $\begin{array}{l}4.1 \% \\
{[0.0-8.6]}\end{array}$ & 179 & 0 & 0.0 & 12 & $\begin{array}{l}6.7 \% \\
{[3.0-10.4]}\end{array}$ & 0 & 0.0 \\
\hline $\begin{array}{l}\text { Sand martin } \\
\text { Riparia riparia }\end{array}$ & 4 & 0 & - & 0 & $0.0 \%$ & 0 & - & 2 & 0 & 0.0 & 0 & $0.0 \%$ & 0 & 0.0 \\
\hline $\begin{array}{l}\text { Banded martin } \\
\text { Riparia cincta }\end{array}$ & - & - & - & - & - & - & - & 7 & 0 & 0.0 & 0 & $0.0 \%$ & 0 & 0.0 \\
\hline $\begin{array}{l}\text { White-throated swallow } \\
\text { Hirundo albigularis }\end{array}$ & - & - & - & - & - & - & - & 1 & 0 & 0.0 & 0 & $0.0 \%$ & 0 & 0.0 \\
\hline Total & 211 & 5 & $\begin{array}{l}2.4 \% \\
{[0.3-4.4]}\end{array}$ & 2 & $\begin{array}{l}0.9 \% \\
{[0.0-2.3]}\end{array}$ & 11 & $\begin{array}{l}5.2 \% \\
{[2.2-8.2]}\end{array}$ & 206 & 0 & 0.0 & 13 & $\begin{array}{l}6.3 \% \\
{[3.0-9.6]}\end{array}$ & 0 & 0.0 \\
\hline
\end{tabular}

For each pathogen and host species, the number of bird sampled (n) and the number of positive (Pos.) are given as well as the infection ratio (Inf. Ratio) and the confidence interval at 95\% [CI 95\%] 
Table 2. Positive Results Presented According to the Type of Swab (Cloacal and Tracheal).

\begin{tabular}{lcrr}
\hline & Tracheal & Cloacal & Both \\
\hline AIV & 2 & 2 & 1 \\
WNV & 1 & 1 & - \\
APMV-1 & $1 / 6$ & $6 / 4$ & $4 / 3$ \\
\hline
\end{tabular}

For APMV-1, the first number indicates results for the February 2010 batch and the second number for the October 2011 batch

lions of individuals (Bijlsma and van den Brink 2005). Swallows and martins often nest in close association with people in cities, towns and villages, including inside the home (e.g. roofs eaves) providing potential pathogen transmission to domestic animals and humans.

Despite these epidemiological risk factors, their susceptibility to avian pathogens has been poorly investigated. No positivity for WNV was detectable in swallow species in Europe and Africa (Balanca et al. 2009, Chevalier et al. 2009). Similarly, little information is available on APMV-1 in these species, but it is hypothesised that most bird species are susceptible to this pathogen (Kaleta and Baldauf 1988). In a large dataset on AIV in wild birds across the world (http://dx.doi.org/10.5061/dryad.58g12), (Caron et al. 2017) hirundinidae tested positive for low pathogenic AIV in several studies, with a RT-PCR infection ratio of $1.29 \%$, revised to $1.50 \%$ with the present study.

During a longitudinal study of AIV in wild and domestic bird populations at two lakes close to Harare, Zimbabwe (details here Caron et al. 2010, 2012), the presence and behaviour of hirundinidae at the study sites were observed (Fig. 1) and a protocol was designed to screen populations of resident and migratory hirundinidae for a set of three important infectious pathogens: AIV, APMV-1 and WNV. More specifically, these species were identified on both ecological and epidemiological grounds as potential bridge hosts for AIV, with the capacity to transmit the viruses from the maintenance host (i.e. ducks) to poultry (Caron et al. 2015, 2017). Birds ( $n=417)$ from five species (Hirundo albigularis, Hirundo rustica, Riparia cincta, Riparia paludicola, Riparia riparia) were captured by mist nets and sampled in February 2010 and October 2011 (Table 1) at a large roosting site estimated to consist of several dozens of thousand of birds. In October, migratory birds (i.e. barn swallows) have just arrived form their Palearctic breeding sites (Fig. 1) and in February, they had been at their wintering ground for $4-5$ months and at the end of their stay in the southern hemisphere.
Cloacal and tracheal swabs were collected from each captured bird. Swabs were placed in viral transport medium (phosphate-buffered saline, glycerol and antibiotics), kept on ice and subsequently placed in liquid nitrogen prior to shipment to the laboratory for testing. The batch from the 2010 mission was sent to the Onderstepoort Veterinary Institute. There, RNA was extracted using a Magna-Pure LC robotic system (Roche, USA). A singletube triplex RT-PCR technique for the three pathogens was used. Vetmax RT-PCR kits (LifeTechnologies) were used in conjunction with the primer and probe sets described for APMV-1 (Fuller et al. 2010), AIV (Spackman et al. 2003) and WNV (Zaayman et al. 2009). Probes had been fluorogenically labelled with FAM, VIC or NED and reactions were analysed on a StepOnePlus machine (LifeTechnologies). Samples were considered positive if a clear logarithmic curve was observed in relation to the negative and positive controls, and a $\mathrm{Ct}$ value of $<35$ was assigned. The batch from the 2011 mission was sent to the Istituto Zooprofilattico Sperimentale dell'Abruzzo e del Molise, Italy. Once purified by the High Pure Viral Nucleic Acid Kit (Roche, USA), the RNA was used to detect WNV (Eiden et al. 2010) and AIV and APM-1 (TaqMan ${ }^{\circledR} \mathrm{NDV}$ Reagents, Ambion, USA). Unclear tests were repeated. The rate of infection was calculated as the percentage of positive individuals compared with the total number of individuals tested.

Results for each species, pathogen and by swab type are given in Tables 1 and 2. All birds were apparently healthy during the handling and were released successfully. We detected all three pathogens in Hirundo rustica, AIV and APMV-1 in Riparia riparia and no viruses in the smaller sample size of the remaining 3 species. To our knowledge, apart from AIV in Hirundo rustica, this is the first time that these pathogens were detected in these species. Of interest, none of the birds sampled had a co-infection of these pathogens.

The ecosystem we studied has previously been shown to harbour a continuous circulation of AIV in wild birds 
(Caron et al. 2011, 2012), probably not only in Anseriformes species as expected, but also in populations of species not usually considered as maintenance hosts. The results presented here point at hirundinidae species as candidate for such a contribution in a maintenance com-munity for AIV (Caron et al. 2017), given not only the presence of AIV detected, but also their life-history traits. The potential for NCD maintenance and spread by wild birds is suspected (Cappelle et al. 2015), but the assay we applied (Fuller et al. 2010) detects both classes and all genotypes of APMV-1, including the avirulent strains typically associated with wild waterfowl. WNV amplifica-tion in wild birds is known on the American continent (Reed et al. 2003).

The large roost from which birds were sampled offers a massive density of multi-species host populations that pathogens could use to be maintained. In addition, all five host species undertake intercontinental migration (Hirundo rustica) or nomadic movements within Africa (Hockey et al. 2005). Pathogens harboured in these populations could therefore spread across regions and continents. Fi-nally, hirundinidae can also potentially transmit those pa-thogens to important populations of veterinary or public health concern (e.g. Caron et al. 2015, 2017) through the frequenting of farms or village buildings. The absence of AIV and WNV shortly after the arrival of Palearctic migrants (Hirundo rustica) in the ecosystem can probably be explained by a small sample size of Hirundo rustica in October 2011; alternatively, by seasonal dynamics in pathogens' prevalence (although AIV have been previously observed circulating during this season, (Caron et al. 2011).

The particular behaviour of these species being mostly aerial, points to questions on how they get infected. The transmission pathways from swallows towards other hosts including humans can occur through infected faecal material deposited on a surface. However, the transmission pathways towards swallows could be much more limited. Swallows do not have much direct contact with other birds (except other swallows) or potentially infected environments. These limited potential pathways leading to an infection of hirundinidae from other hosts can be summarised as follows: i) infection through insect bites (e.g. mosquito for WNV); ii) drinking from surface water (e.g. AIV can be maintained in water Lebarbenchon et al. 2011; Nazir et al. 2011); however, in open (not shallow) water where swallows are most likely to drink while flying, a dilution effect could reduce the risks of infection; iii) finally, at breeding sites, from mud collected from shallow waters and transported in their throat to make their nests (where AIV and APMV-1 have more chances to be maintained in sediment than open water). If this infectious bottleneck is confirmed, one could hypothesise that pathogens possibly evolve in a relatively closed host pool exclusively through intra- and interspecies transmission within hirundinidae populations or communities. Unfortunately, no viruses were isolated from our samples and we could not compare them with other viruses from wild birds. These behavioural peculiarities seen under an epidemiological prism are shared with other animals including bats. Radiation of pathogens in a range of hosts has been shown to originate from bat species, and bats are considered a maintenance host for many pathogens (EscaleraZamudio 2016, Munster et al. 2016).

Swallows and martins are ubiquitous in many ecosystems including in agricultural landscapes. Our results call for more investigation of hirundinidae communities and their pathogens as they could play a role in the maintenance and transmission of pathogens of relevance. What is the effect of migration on the prevalence of these pathogens in these hosts? Are these viral strains part of broader pool maintained in wild birds, domestic poultry or both? What are the infectious transmission pathways from and to swallow populations?

\section{Acknowledgements}

This work was undertaken in the framework of the Research Platform "Production and Conservation in Partnership" (www.rp-pcp.org) and funded by the FSP-GRIPAVI (Ministe`re Franc, ais des Affaires Etrange`res).

\section{References}

Balanca G, Gaidet N, Savini G, Vollot B, Foucart A, Reiter P, Boutonnier A, Lelli R, Monicat F (2009) Low West Nile Virus circulation in wild birds in an area of recurring outbreaks in southern France. Vector and Vector-Borne Diseases 9:737-741

Bijlsma RG, van den Brink B (2005) A barn swallow Hirundo rustica roost under attack: timing and risks in the presence of African Hobbies Falco cuvieri. Ardea 93:37-48

Boyd, J. H. 2015. Taxonomy in Flux Checklist 3.02.

Cappelle J, Caron A, Servan De Almeida R, Gil P, Pedrono M, Mundava J, Fofana B, Balanca G, Dakouo M, Ould El Mamy AB, Abolnik C, Maminiaina OF, Cumming GS, De Visscher MN, Albina E, Chevalier V, Gaidet N (2015) Empirical analysis suggests continuous and homogeneous circulation of Newcastle disease virus in a wide range of wild bird species in Africa. Epidemiol Infect 143:1292-1303 
Caron A, Abolnik C, Mundava J, Gaidet N, Burger CE, Mochotlhoane B, Bruinzeel L, Chiweshe N, de Garine-Wichatitsky M, Cumming GS (2011) Persistence of low pathogenic avian influenza virus in waterfowl in a Southern African ecosystem. EcoHealth 8:109-115

Caron A, Cappelle J, Cumming GS, de Garine-Wichatitsky M, Gaidet N (2015) Bridge hosts, a missing link for disease ecology in multi-host systems. Veterinary Research 46:83

Caron A, Cappelle J, Gaidet N (2017) Challenging the conceptual framework of maintenance hosts for influenza A viruses in wild birds. Journal of Applied Ecology 54:681-690

Caron A, Cumming GS, Mundava J, Chiweshe N, Mundy P, de Garine-Wichatitksy M (2012) Report on a five-year avian influenza survey in the Manyame catchment. Honeyguide 58:113120

Caron A, de Garine-Wichatitsky M, Gaidet N, Chiweshe N, Cumming GS (2010) Estimating dynamic risk factors for pathogen transmission using community-level bird census data at the wildlife/domestic interface. Ecology and Society 15:25

Chevalier V, Reynaud P, Lefrançois T, Durand B, Baillon F, Balança G, Gaidet N, Mondet B, Lancelot R (2009) Predicting West Nile Virus seroprevalence in wild birds in Senegal. Vector-Borne and Zoonotic Diseases 9:589-596

Eiden M, Vina-Rodriguez A, Hoffmann B, Ziegler U, Groschup MH (2010) Two new real-time quantitative reverse transcription polymerase chain reaction assays with unique target sites for the specific and sensitive detection of lineages 1 and 2 West Nile virus strains. Journal of Veterinary Diagnostic Investigation 22:748-753

Escalera-Zamudio, M., E. Rojas-Anaya, S. O. Kolokotronis, B. Taboada, E. Loza-Rubio, M. L. Mendez-Ojeda, C. F. Arias, N. Osterrieder, and A. D. Greenwood. 2016. Bats, Primates, and the Evolutionary Origins and Diversification of Mammalian Gammaherpesviruses. MBio 7.
Fuller CM, Brodd L, Irvine RM, Alexander DJ, Aldous EW (2010) Development of an L gene real-time reverse-transcription PCR assay for the detection of avian paramyxovirus type 1 RNA in clinical samples. Arch Virol 155:817-823

Hockey PAR, Dean WRJ, Ryan PG (2005) Roberts - Birds of Southern Africa, Cape Town: John Voelcker Bird Book Fund

Kaleta EF, Baldauf C (1988) Newcastle disease in free-living and pet birds. In: Newcastle disease, Alexander DJ (editor), Norwell, Massachisetts, USA: Kluwer Academic Publishers, pp 197-246

Lebarbenchon C, Yang M, Keeler SP, Ramakrishnan MA, Brown JD, Stallknecht DE, Sreevatsan S (2011) Viral replication, persistence in water and genetic characterization of two influenza a viruses isolated from surface lake water. PLoS ONE 6:e26566

Munster VJ, Adney DR, van Doremalen N, Brown VR, Miazgowicz KL, Milne-Price S, Bushmaker T, Rosenke R, Scott D, Hawkinson A, de Wit E, Schountz T, Bowen RA (2016) Replication and shedding of MERS-CoV in Jamaican fruit bats (Artibeus jamaicensis). Sci Rep 6:21878

Nazir J, Haumacher R, Ike AC, Marschang RE (2011) Persistence of avian influenza viruses in lake sediment, duck feces, and duck meat. Appl Environ Microbiol 77:4981-4985

Reed KD, Meece JK, Henkel JS, Shukla SK (2003) Birds, migration and emerging zoonoses: west nile virus, lyme disease, influenza A and enteropathogens. Clinical Medicine Research 1:5-12

Spackman E, Senne DA, Bulaga LL, Myers TJ, Perdue ML, Garber LP, Lohman K, Daum LT, Suarez DL (2003) Development of real-time RT-PCR for the detection of avian influenza virus. Avian Dis 47:1079-1082

Viana DS, Santamaria L, Figuerola J (2016) Migratory Birds as Global Dispersal Vectors. Trends Ecol Evol 31:763-775

Zaayman D, Human S, Venter M (2009) A highly sensitive method for the detection and genotyping of West Nile virus by real-time PCR. J Virol Methods 157:155-160 